\title{
Analysis of Customer Perceptions on the "Quality of Service" in Mobile Communications in Sri Lanka
}

\author{
W Janak Fernando
}

Abstract: As a step towards ensuring a better quality in the highly competitive mobile communications industry, the study was designed to analyze expectations on the quality of the service characteristics in mobile communication of customers in Sri Lanka

Telecom industry is best described as an industry in its growth phase in Sri Lanka, dominating in the service sector as the main contributor for national GDP. Cellular industry has been the engine of growth in the telecommunications industry and has bagged $70 \%$ of the overall telecom industry. Mobile communication is leading the role as prime communication media in Sri Lanka with a penetration of over $30 \%$ in year 2007. Mobile customer base has been increasing at a steady phase over last few years and opportunities are still significant for higher and higher number of customers. Operators are at a race of gaining more and more new markets, consequently the Network expansion and capacity upgrades are also at a higher speed. Motivations are much higher towards low cost solutions, to maintain cost per user and there by be competitive in call charges.

Low cost capacity enhancements are always contradictıng to call quality in mobile communication. Clarity in customer expectation on quality is significant to develop a cost effective balanced network.

Players in the service sector are under increasing pressure to demonstrate that their services are customer-focused and that continuous performance improvement is being delivered. Given the financial and resource constraints under which service organizations must manage it is essential that customer expectations are properly understood and measured and that, from the customers' perspective, any gaps in service quality are identified. This information then assists a service provider in identifying costeffective ways of closing service quality gaps and of prioritizing which gaps to focus on.

Clarity on perception and gap for satisfaction is vital for operators to effectively utilize scarce resources in telecom industry to ensure optimum service to Customers.

\section{Introduction}

\subsection{Evolution of mobile communication}

The first operational cellular communication system was deployed in Norway in 1981 and was followed by similar systems in the United States of America (USA) and United Kindom (UK). These first generation systems provided voice transmissions by using frequencies around $900 \mathrm{MHz}$ and analogue modulation. The second generation ( $2 \mathrm{G}$ ) of the wireless mobile network was based on low-band digital data signaling. The most popular $2 \mathrm{G}$ wireless technology is known as Global Systems for Mobile Communications (GSM).

' $2.5 \mathrm{G}$ ' systems were introduced to enhance the data capacity of GSM and mitigate some of its limitations. These systems add packet data capability to GSM networks, with GPRS (General Packet Radio Service) facility.
Planning for third generation (3G) started in the 1980s. Initial plans focused on multimedia applications such as videoconferencing for mobile phones. When it became clear that the real killer application was the Internet, $3 G$ thinking had to evolve. As personal wireless handsets become more common than fixed telephones, it is clear that personal wireless Internet access will follow and users will want broadband Internet access wherever they go.

Higher data speed is the prime feature of $3 G$ over $2 \mathrm{G}$ systems, and allow ups to $2 \mathrm{Mb} / \mathrm{s}$ for stationary users. High Speed Downlink Packet Access (HSDPA) and High Speed Uplink Packet Access (HSUPA) further enhance the data speeds in downlink and uplink respectively.

Eng. W. Janak Fernando, B.Sc. Eng. (Hons) (Peradeniya), AMIE(Sri Lanka), Manager Access Network operations in Dialog Telekum PLC. 
The second key issue for $3 \mathrm{G}$ wireless is that users will want to roam worldwide and stay connected. Today, GSM leads in global roaming. Because of the pervasiveness of GSM, users can get comprehensive coverage in Europe, parts of Asia and some US coverage. A key goal of $3 \mathrm{G}$ is to make this roaming capacity universal.

A third issue for $3 G$ systems is capacity. As wireless usage continues to expand, existing systems are reaching limits. Cells can be made smaller, permitting frequency reuse, but only to a point. The next step is new technology and new bandwidth.

$4 \mathrm{G}$ is the short term for fourth-generation wireless, the stage of broadband mobile communications that will supersede the 3G. While neither standards bodies nor carriers have concretely defined or agreed upon what exactly $4 \mathrm{G}$ will be, it is expected that end-to-end IP and high-quality streaming video will be among $4 \mathrm{G}^{\prime} \mathrm{s}$ distinguishing features.

\subsection{Quality of service in Telecommunication} International Telecommunications Union gives a following definition for quality of service (QOS):The collective effect of service performance which determines the degree of satisfaction of a user of a service (ITU-T, G.1000)

QOS at first appears to be a clear, unambiguous concept. However, even a brief review of literature reveals that QoS is an extremely overloaded term with no generally agreed meaning. (TeleManagement Forum 2005)

QoS is a term that is well known but difficult to define completely. The problem is that both the words 'quality' and 'service' are themselves open to many interpretations. (Willis 2005)

\subsection{Importance of QOS in mobile communication}

Compared to wire line communication quality of service, management is more sophisticated in wireless communication. For Mobile communication quality of service management is further complicated due to the prime feature of Handover which allow customer mobility (to move from one cell to another) without service interruption.

In fixed communication, the user is stationary, hence easy to monitor user based quality of service characteristics. But in Mobile communication the user can be at any place of the network, at any given time. Therefore the quality of service should be maintained in whole network, to ensure better quality.

Customer behavior and movement pattern is another important factor to be considered for a guaranteed quality of service. With industrialization most of the commercial towns are heavily congested during business hours and almost empty in non-working hours or holidays. The Mobile Network capacity should be in place to cater for peak hour business traffic with sufficient quality, but will be idling at non-business hours. Above network capacity requirement is a costly affair for Mobile operators and they invariably offer cheap tariffs at nonbusiness hours and higher rates at business hours to distribute traffic and to utilize network resources evenly round the clock.

Typically, mobile operators are focusing on geographical area wise QoS rather than per user QoS which is really hard to achieve due to user mobility.

\section{Research problem}

After the liberalization, today's players in the cellular market are faced with a multitude of challenges in the atmosphere of open competition. Network operators are forced to continuously conceive and adopt new ways of differentiating their services and perhaps more importantly, sustaining their customers. The net result of these developments has brought in a greater emphasis on "quality" - interpreted as better customer relations, enhanced services under the Value-Added service portfolio, and more flexible packaged offerings. There is however another direct quality differentiator, which is in fact more visible - "call quality". In the mobile environment, call quality is an absolute benchmark, giving the customer the opportunity to compare one service directly with another. Dropped calls mean lost customers, giving the quest for improved call quality a greater significance.

The economics involved in acquiring a new customer are, quite frankly, awesome from the business perspective. The investment required by the mobile operator is substantial in terms of advertising, commissions, handset subsidies, not to mention routine administration. Making the investment pay relies on retaining the customer 
long enough by offering lower prices, more attractive services, more responsive customer care, better billing - if the call quality does live up to expectations, the customer has plenty of other choices. Churn is without doubt a deadly enemy in the game of customer retention.

Additional quality in mobile industry is always linked with extra investment for the operator and consequently on the customer. Clear understanding of customer expectations and perceptions on quality, will lead to balance the value for money in mobile industry.

\subsection{Objectives of study}

i. To find out how quality of service characteristics rank by mobile customers in Sri Lanka.

ii. To identify the real customer expectations on quality of service characteristics of Mobile communication, by analyzing customer perceptions and satisfaction.

iii. Based on above, to recommend operators to whether to invest on quality.

\subsection{Significance of the study}

Managers in the service sector are under increasing pressure to demonstrate that their services are customer-focused and that continuous performance improvement is being achieved. Given the financial and other resource constraints, under which service organizations must manage, it is essential that customer expectations are properly understood and measured Also it is equally import that based on the customer perceptions, any gaps in service quality are identified. This information then assists a manager in identifying cost-effective ways of closing service quality gaps and of prioritizing which gaps to focus on - a critical decision, given the scarce resources.

Mobile communication is the key driver in the communication sector in Sri Lanka. Therefore clarity on customer expectations and any quality of service gap in the industry is pivotal for the benefit of both service providers and mobile users. The significance of the study is further leveraged by emerging lip services on poor quality in mobile communication.

\subsection{Main partners}

The Telephone Network market is clearly subject to increasing dominance by the mobile sector, largely due to the rapid enhancement of affordability, availability and accessibility of mobile services relative to fixed services over the past years.

The mobile sector consists of four mobile operators, Celltel Lanka (Private) Limited, Dialog Telecomlimited,HutchinsonTelecommunications Lanka (Private) Limited, and Mobitel (private) Limited. Airtel India also being licensed as the fifth mobile operator in Sri Lanka recently, but yet to start the services. The mobile sector accounts for around $70 \%$ of the total telephony subscriber base in Sri Lanka.

Cellular industry has been the engine of growth in the telecommunications industry.

Figure-01 illustrates the percentage contribution of fixed and mobile communication in Sri Lankan telecom sector. Fixed phones dominated the market at the early stages, but aggressively captured by the mobile communications at midway. CDMA could be the reason behind the slightly flatter variation at the latter part.

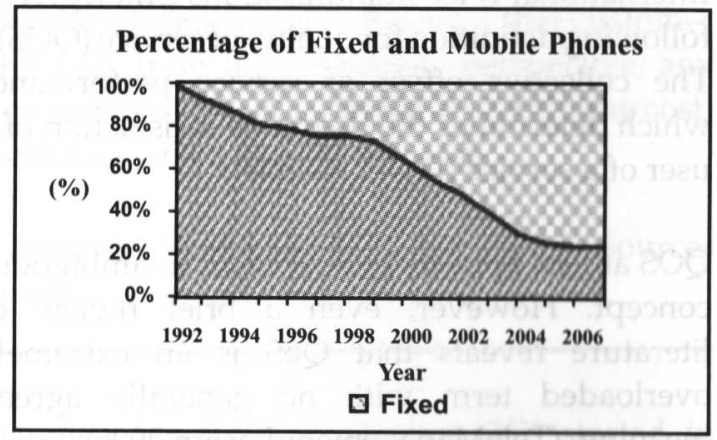

Figure-01 Percentage of Mobile and Fixed phones

\section{LITERATURE SURVEY.} What is Perception?

The Merriam-Webster collegiate dictionary defines perception as "a result of perceiving." Perceive in tern is defined as "to regard as being such" or "to attain awareness or understanding of" Borgatti(1996) defines perception as "a person's mental image of the world". This definition highlights the subjective nature of perception.

\section{The Perception Gap in Telecommunication}

A perception gap is a gap that occurs when the telecommunications service provider perceives something different. Clearly, quality is at stake when these gaps exist. 
Theconcept of customerperception is interrelated with other customer concepts such as customer satisfaction and service quality. However the inter-relationship between customer satisfaction and service quality is not always clear, with some authors claiming that quality is a function of satisfaction while others that quality determines satisfaction. (Tuomi 2001).

\subsection{What is QOS}

Service quality is a concept that has aroused considerable interest and debate in the research literature because of the difficulties in both defining it and measuring it with no overall consensusemerging on either (Wisniewski, 2001). There are a number of different "definitions" as to what is meant by service quality. One that is commonly used defines service quality as the extent to which a service meets customers' needs or expectations (Lewis and Mitchell, 1990; Dotchin and Oakland, 1994a; Asubonteng et al ., 1996; Wisniewski and Donnelly, 1996). Service quality can thus be defined as the difference between customer expectations of service and perceived service. If expectations are greater than performance, then perceived quality is less than satisfactory and hence customer dissatisfaction occurs (Parasuraman et al ., 1985; Lewis and Mitchell, 1990).

Always there exists an important question: why should service quality be measured? Measurement allows for comparison before and after changes, for the location of quality related problems and for the establishment of clear standards for service delivery. Edvardsen et al . (1994) state that, in their experience, the starting point in developing quality of services is analysis and measurement.

\subsection{Methods - Measure of Customer Satisfaction}

What is service quality? Prior studies concerning this concept have defined it in different ways because of the research's needs. From economist's point of view, Kihlstrom and Levhari (1977), suggested that quality should be treated as a linear function describing the service provided by a given commodity unit. Along similar lines, Sheshinski (1976) pointed out that quality can be conceived as a scalar index representing several attributes. From the strategic point of view, Garvin (1987) proposed that "quality means pleasing consumers, not just protecting them from annoyances." Quality should be managed at the strategic level instead of the operational level.

\section{Methodology}

\subsection{Theoretical Background}

The different QOS models had their own advantages, disadvantages and applicability in the context of the underlined study. The studies on quality of service in the Telecommunication sector are very seldom or not at all. The author could not find any readily available research on quality of service in mobile communication in the Sri Lankan context.

\section{QOS Characteristics}

Quality of service is comparatively sophisticated in mobile communication compared to other Telecommunication technologies. The subject also spreads over a wider area and plays a leading role for the success of all features and technologies in mobile communication. Since the subject is spread over a wider area, decisions on focus area is vital for the success of the research. Therefore the author carefully selected the serveability part from ITU-T Recommendation E.800 framework for the study.

Serveability has been defined as the main part of the QOS framework in ITU-T recommendations. Serveability performance has a direct relation on offered service by the operators, and also operators can optimize relevant parameters to ensure improved service levels. Fine tuning of Serveability performance characteristics in an effective manner with clear understanding, of customer expectation will lead to the overcoming of identified research problems of the study.

Serveability is further subdivided into three terms

\section{i. Service accessibility Performance \\ ii. Service retainability Performance \\ iii. Service integrity Performance}

\section{Relationship on Perception, expectation}

SERVQUAL Gap analysis model which was developed by Parasuraman et al. (1985) has been widely used for service quality researches. The Model was further developed by ASI Quality Systems, (1992), Curry (1999), Luk and Layton, (2002). Gap5 of the module has been defined as the most important gap and pertains to the customer, as such is considered to be the true measure of service quality. 
Therefore Gap5 of SERVEQUAL gap analysis model has been selected to analyze the relationship between customer perception and expectation. Customer perception and level of satisfaction on quality of service characteristics in mobile communication is directly taken as an input for the questionnaire.

As per the model,

Expectation - Perception $=$ Gap5

i.e. the gap5 is the gap between customer expectations on quality of service and perception level. And gap is defined in such a way that to represent service level improvements required to achieve customer expectation levels from current perception levels. Satisfaction comes in to the picture when perception is higher than expectation. Therefore the same expression can be represented as

Perception - Expectation $=$ Satisfaction

And

Expectation $=$ Perception - Satisfaction

\subsection{Sample of the Study}

The total population of the study included all mobile phone users in Sri Lanka during the time of study. Due to constraints in time frame, 400 mobile users were targeted from all nine provinces of the Island for the study. However it managed to successfully collect 438 answers ( 94 from Colombo and 342 from out of Colombo), covering all nine provinces in the Island.

\section{Data Analysis and user Questionnaire}

\subsection{Ranking}

One of the main objectives of the research is to determine how Sri Lankan mobile customers would like to prioritize 'quality of service' characteristics. The questionnaire was designed in such a way that Poor coverage, Call originating failure, Call drops during call and poor quality of voice can be prioritize-based on customers' expectations. And also flexibility was given to specify any additional characteristics on customers' point of view.

\subsubsection{Ranking as Sri Lankan Mobile User}

The outcome of the ranking illustrated in Figure02. Poor coverage has been ranked significantly over other characteristics to be eliminated to improve quality of service. Call originating failure and Call drop during call has been almost equally ranked and poor quality of voice was ranked as the least prioritized, but still this cannot be marginalized as the percentage is significant.

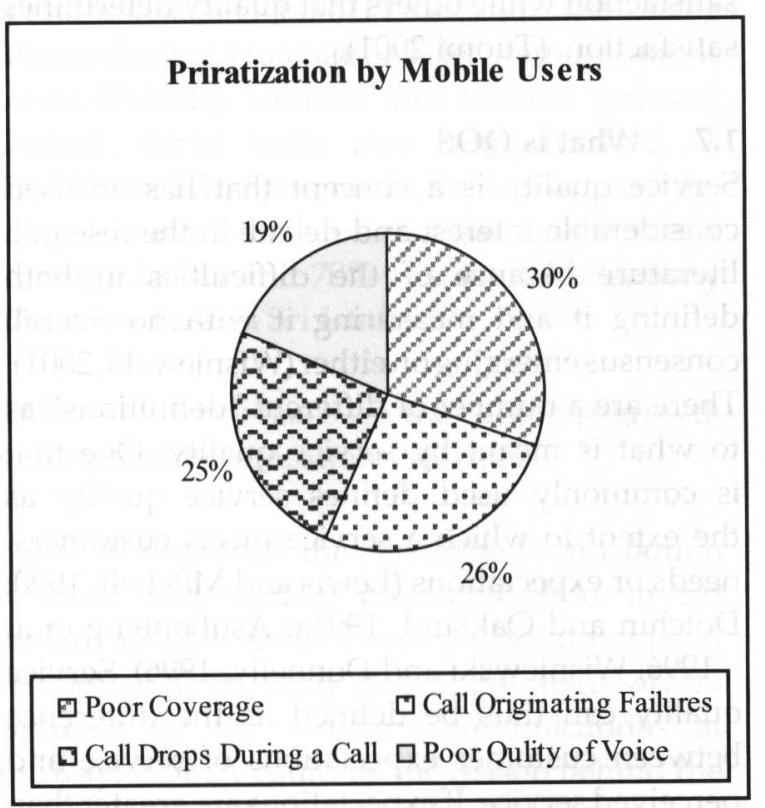

Figure-02 Ranked by Mobile Users

Apart from above four characteristics, few candidates highlighted Echo on calls as an important characteristic to be eliminated. Low data speed of GPRS service, Cross connections, long connecting time are also identified as additional characteristics by a few candidates.

Significant weightage has been given to eliminate call originating failure.

\section{Ranking as Sri Lankan Mobile Network Users.}

Above ranking was further analyzed to probe how users in different mobile Networks in Sri Lanka rank QOS characteristics. Figure-03 delineates the outcome. QOS characteristics are prioritized in the same order, by users in all mobile Networks, apart from Dialog Network. Call originating failure has been ranked slightly more important than the poor converge in Dialog Network. Priority given to poor coverage $(44 \%)$ by Mobitel customers is another exceptional outcome compared to other Networks. Poor quality of voice has been ranked by Tigo and Hutch users almost similar to other characteristics. 


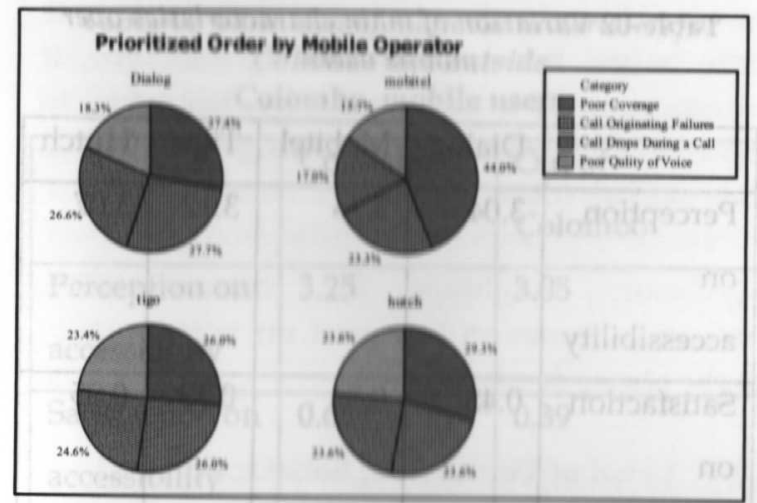

Figure-03 Rank by User of mobile operators

\subsubsection{Ranking as Colombo and outside Colombo Mobile users.}

Ranking was further analyzed to probe how Colombo and outside Colombo customers Value QOS characteristics. Call drop during a call has been ranked as the main characteristic to be eliminated by Colombo Mobile users while poor coverage as expected, by Outside Colombo Mobile users. Weightage given by outside Colombo users to eliminate poor quality of voice is significant compared to Colombo mobile user.

All mobile operators guaranteed sufficient coverage in Colombo area. But still Colombo users also have given a higher percentage to eliminate poor coverage. This higher percentage can be mainly due to their life style, the questionnaire was asked to fill by using last six months experience of mobile communication. Most of mobile users in Colombo area had been traveling outside Colombo at a substantial rate, though they most frequently used phones inside Colombo.

Higher values given by outside users for poor coverage further reiterates inadequate mobile coverage in rural areas and can be considered as a message for mobile service providers to further expand their coverage.

Call originating failure has been ranked at a higher rate by both parties irrespective of the location. Sufficient capacity to ensure end to end non-blocking connection is the expectation of customers. Significant weightage for voice quality motivates operators to invest on voice quality by the research outcome.

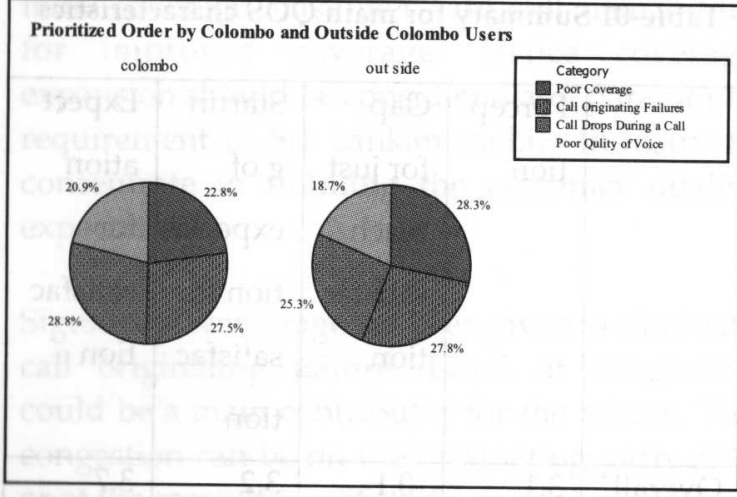

Figure-04 Rank by User of Colombo and Outside Colombo

\subsection{Level of Perception, Satisfaction and Expectation.}

Identification of real customer expectations on quality of service characteristics by analyzing customer perceptions and satisfaction is a prime objective of the research. The Perception and satisfactory level of each 'quality of service' characteristic, has been directly taken as inputs of the questionnaire then. Expectations for each characteristic was calculated as per the relationship of three characteristics.

The questions were based on five point likert scale for perception (five being the strong positive perception and 1 being the strong negative perception). Satisfaction also based on a five point likert scale (where 2 being the very satisfied and -2 being the very dissatisfied states).

\section{Level of Perception, Satisfaction and Expectation as Sri Lankan Mobile users}

The average values of main characteristics are listed in Table-01. With the outcome it is clear that the exiting perception level of the main that 'Quality of service' characteristics are below the expectation level. Gap has been calculated for each main characteristic to just reach satisfaction level and thereby calculate the starting point of expectation for satisfaction. The target expectation level is the mean of just the starting point for satisfaction and very satisfied, therefore slightly above the starting point of satisfaction expectation.

Retainability has the most significant gap compared to the other two characteristics. 
Table-01 Summary for main QOS characteristics

\begin{tabular}{|l|l|l|l|l|}
\hline & Percep & $\begin{array}{l}\text { Gap } \\
\text { tion } \\
\text { for just } \\
\text { reach } \\
\text { satisfac } \\
\text { tion }\end{array}$ & $\begin{array}{l}\text { Startin } \\
\text { g of } \\
\text { expecta } \\
\text { tion for } \\
\text { satisfac } \\
\text { tion }\end{array}$ & $\begin{array}{l}\text { Expect } \\
\text { ation } \\
\text { for } \\
\text { tion }\end{array}$ \\
\hline $\begin{array}{l}\text { Overall } \\
\text { accessib }\end{array}$ & 3.1 & -0.1 & 3.2 & 3.7 \\
\hline $\begin{array}{l}\text { Overall } \\
\text { Retaina } \\
\text { bility }\end{array}$ & 3.2 & -0.5 & 3.7 & 4.2 \\
\hline $\begin{array}{l}\text { Overall } \\
\text { Integrit } \\
\text { y }\end{array}$ & 3.4 & -0.1 & 3.5 & 4.0 \\
\hline $\begin{array}{l}\text { Over } \\
\text { QOS }\end{array}$ & 3.2 & -0.2 & 3.4 & 4.0 \\
\hline
\end{tabular}

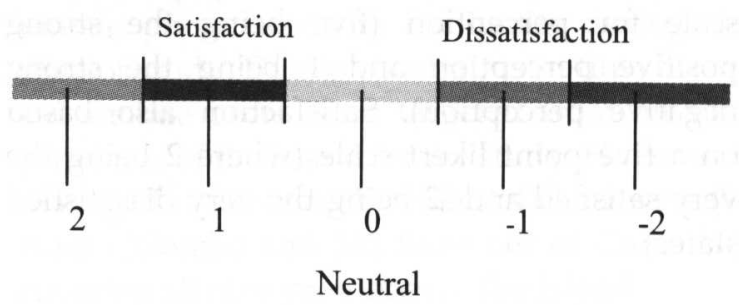

Figure-05 Scale of Satisfaction

\subsubsection{Level of Perception Satisfaction and Expectation as Sri Lankan Mobile Network users}

The output has been further analyzed in detail as given Table- 02 and Table- 03 . Table- 02 illustrates perception and satisfaction levels of users in different mobile Networks in Sri Lanka. According to the scale used 0 represent neither satisfied nor dissatisfied state (neutral) and 0.5 and -0.5 represent just satisfaction and just dissatisfaction levels respectively. Overall Satisfaction level of Hutch customers are slightly towards Dissatisfaction level from the neutral point, whereas all others are slightly towards satisfaction. Tigo customers' level of satisfaction of retainability and integrity is also slightly towards dissatisfaction. Mobitel has achieved the highest overall perception and Satisfaction levels.
Table-02 Variation of main characteristics over mobile users

\begin{tabular}{|c|c|c|c|c|}
\hline & Dialog & Mobitel & Tigo & Hutch \\
\hline $\begin{array}{l}\text { Perception } \\
\text { on } \\
\text { accessibility }\end{array}$ & 3.04 & 3.26 & 3.12 & 3.07 \\
\hline $\begin{array}{l}\text { Satisfaction } \\
\text { on } \\
\text { accessibility }\end{array}$ & 0.43 & 0.54 & 0.39 & 0.05 \\
\hline $\begin{array}{l}\text { Perception } \\
\text { on } \\
\text { retainability }\end{array}$ & 3.14 & 3.30 & 3.15 & 3.16 \\
\hline $\begin{array}{l}\text { Satisfaction } \\
\text { on } \\
\text { retainability }\end{array}$ & 0.06 & 0.1 & -0.01 & -0.06 \\
\hline $\begin{array}{l}\text { Perception } \\
\text { on integrity }\end{array}$ & 3.41 & 3.64 & 3.52 & 3.49 \\
\hline $\begin{array}{l}\text { Satisfaction } \\
\text { on integrity }\end{array}$ & 0.5 & 0.59 & -0.03 & -0.2 \\
\hline $\begin{array}{l}\text { Perception } \\
\text { Overall }\end{array}$ & 3.19 & 3.34 & 3.27 & 3.30 \\
\hline $\begin{array}{l}\text { Satisfaction } \\
\text { Overall }\end{array}$ & 0.31 & 0.42 & 0.26 & -0.06 \\
\hline
\end{tabular}

Level of Perception Satisfaction and Expectation as Colombo and outside Colombo Mobile users

Table- 03 elaborates perceptions and satisfaction levels of mobile users in Colombo and outside Colombo. The overall satisfaction levels of mobile customers in Colombo is just above the minimum of satisfaction levels. This is the only selected mobile users' cluster whose satisfaction is above the lower levels of satisfaction. Outside Colombo mobile users' level of satisfaction is also towards the direction of satisfaction from the neutral point.

Both overall perception and satisfaction levels of Colombo users are higher than outside Colombo users which is an expected outcome. 
Table-03 Variation of main characteristics for Colombo and outside

Colombo mobile users

\begin{tabular}{|l|l|l|}
\hline & Colombo & $\begin{array}{l}\text { Out of } \\
\text { Colombo }\end{array}$ \\
\hline $\begin{array}{l}\text { Perception on } \\
\text { accessibility }\end{array}$ & 3.25 & 3.05 \\
\hline $\begin{array}{l}\text { Satisfaction on } \\
\text { accessibility }\end{array}$ & 0.66 & 0.39 \\
\hline $\begin{array}{l}\text { Perception on } \\
\text { retainability }\end{array}$ & 3.14 & 3.17 \\
\hline $\begin{array}{l}\text { Satisfaction on } \\
\text { retainability }\end{array}$ & 0.25 & 0.031 \\
\hline $\begin{array}{l}\text { Perception on } \\
\text { integrity }\end{array}$ & 3.51 & 3.44 \\
\hline $\begin{array}{l}\text { Satisfaction on } \\
\text { integrity }\end{array}$ & 0.68 & 0.38 \\
\hline $\begin{array}{l}\text { Perception } \\
\text { Overall }\end{array}$ & 3.33 & 3.21 \\
\hline $\begin{array}{l}\text { Satisfaction } \\
\text { Overall }\end{array}$ & 0.53 & 0.26 \\
\hline
\end{tabular}

\section{$4 \quad$ Final Result and Recommendation}

\section{$4.1 \quad$ Ranking}

Ranking was analyzed, based on three categories. The outcome of the analysis discussed under each sub category as given below.

\subsubsection{Outcome as Sri Lankan Mobile User}

Based on this study result, it is clear that customers have given a clear indication for mobile service providers in Sri Lanka. The poor coverage is the main QOS issue to be eliminated over other main characteristics (refer Figure02). Coverage enhancement is a challenge in mobile communication compared to fixed communication because of the supreme feature of mobility. The same customer can be demanding continuous coverage for multiple geographical areas based on customer mobility, where as only one or two fixed locations have been expected the connections in fixed communication.

Despite the operators environmental thrust on expansion of both land mass and population mass coverage, customers are still demanding for improved coverage. Hence coverage expansion should be considered as a paramount requirement in Sri Lankan mobile Industry to concentrate in fulfilling the customer quality expectations.

Significant weightage has been given to eliminate call originating failure. Level of congestion could be a main contributor for the failure. The congestion can be on the originating party side or at the receiving party side, or even may be on an operator interconnection route or in a switch element in between. Network operators should ensure recommended GOS (grade of service) or in other words the blocking probability even at the peak traffic hour. (Telecommunication Regulatory Commission) TRC can play a major role to eliminate congestion levels on inter operator connections.

Call drop also ranked at a percentage of almost equal as call originating failure, without any doubt call drop rate should be maintained at a lower level. All three characteristics discussed so far is inextricably linked, Therefore to maintain call drop rate at an acceptable level, coverage and congestion levels should also be maintained at satisfactory levels.

Apart from above characteristics, quality of voice also has been ranked by Sri Lankan mobile users at a substantial level, giving an indication to service providers to keep an eye on it. Basic level of voice quality from merely telecom equipment itself is questionable for given higher weightage. Additional Voice Quality Equipments will directly improve QOS of some characteristics of mobile communication.

Also the indication given by few users, 'echo' as one of the main concerns to be eliminated, should be considered in a positive manner. Even though echo is not as bad as the early days of GSM, still not reach users' expectation level. Additional Voice quality enhancement tools, guarantee an echo free mobile Network.

\section{Outcome as Sri Lankan Mobile Network Users.}

Outcome of the ranking of QOS characteristics by users in different mobile Networks is illustrated in figure-03. With the above outcome, mobile service providers can concentrate on following 
Dialog outcome can be due to existing levels of congestion as a result of their higher customer base, Capacity and Coverage enhancement should be treated as equaly important. New surrounding sites for existing highly congested sites would gain better result. Antenna height reduction, tilt variations on higher elevated sites in parallel to surrounding low elevated sites may harvest better traffic distribution patterns. Despite the offer of the widest coverage which is considerably above all other service providers, still customer expected more and more coverage.

Obviously, Mobitel customers given a clear indication to enhance their coverage over all other characteristics, call originating failure in also comparatively ranked at a higher level and should be treated at a higher priority. Comparatively the lowest percentage to call drop rate is a positive indication for Mobitel.

Hutch customers also ranked poor coverage considerably above other characteristics, giving an indication for wider coverage.

Tigo and Hutch customers have given a comparatively higher weightage to poor quality of voice than other two mobile operators and can be considered as an indication for comparatively poor voice quality in their Networks. Telecom equipment used in the Network and the combination of different Network radio parameters to achieve economic requirement, can be reasons for poor voice quality.

\subsubsection{Outcome as Colombo and outside Colombo Mobile users.}

Higher value given by outside users (refer figure-04) for poor coverage, further reiterates inadequate mobile coverage in rural areas and can be considered as a message for mobile service providers to further expand their coverage.

Call originating failure has been ranked at a higher rate by both parties irrespective of the location. Sufficient capacity to ensure end to end non-blocking connection, is the expectation of customers. The congestion may be only during the peak hours and may last within the two or three hours. But with the survey outcome, it is important to ensure sufficient resources to maintain an acceptable originating success rate, even at Peak traffic hours.

Significant weightage for voice quality, motivates operators to invest on voice quality by the research outcome.

\subsection{Level of Perception, Satisfaction and Expectation.}

Sri Lankan mobile users, given the lowest satisfaction for call retainability (refer Table-01), and also call drop while moving, has recorded the highest gap and the perception level is at a very lower level, giving operators' a clear indication to concentrate on Handover relationships and relevant mobility mechanisms.

Smooth functionality of hand over relationships is vital for a quality mobile Network. Lack of proper Neighbor cells, invites drop calls in spot or less coverage areas, and on the other hand, higher numbers of Neighbor relations, sophisticates the best cell selection process, in highly dense coverage areas. Fine tuning of handover relation with an extra effort is paramount for an optimized Network. In depth understanding of the radio parameter is essential for a successful fine-tuning.

Higher dependency on Microwave transmission due to lack of robust Optical Fiber connections and commercial power instability, can be a valid reasons for lower level of perception on temporary network outage. Adequate commercial power unavailability motivates operators to run full time generators option to keep momentum in new site addition and capacity expansion plans, but enhancing operational difficulties at the same time.

Highest perception and Satisfaction level of cross connection can be considered as a recommendation given for success of telecom network implementation and for the latest technologies being used.

Tigo and Hutch operators are advised to concentrate on recorded satisfaction levels towards dissatisfaction from neutral point, (refer Table-02). The deviation of satisfaction on integrity from neutral point, of Hutch users is highly significant. 
Both overall perception and satisfaction levels of Colombo mobile users are higher than outside Colombo users. It is important for mobile operators to improve satisfaction level of outside Colombo users, to actively withstand on prevailing competition in mobile communication industry.

\section{Conclusion}

'Quality of service' characteristics has been ranked in a prioritized order of Poor coverage, Call originating failure, Call Drops and poor quality of voice by Sri Lankan mobile users as a whole. Dialog customers ranked call originating failure slightly above poor coverage while customers in other networks ranked poor coverage as number one and followed the same order as the entire mobile customer base. Mobitel customers have been given a considerable higher percentage for poor coverage. Colombo customers ranked call drop at a higher priory while poor coverage by outside Colombo customers.

Overall customer satisfaction is towards satisfaction from the neutral point, but need further improvement even to just reach satisfaction. Satisfaction level of retainability is at the lowest, among considered main quality of service characteristics. Perception level is just above the mid point of likert scale for all operators. Satisfaction level of Hutch is slightly towards dissatisfaction from the neutral point while towards satisfaction for other three operators. Mobitel achieved the highest level of satisfaction. Colombo mobile users are the only cluster, at least to just reach the satisfaction for the entire study.

\section{References}

1. Antony Oodan, Keith Ward, Catherine Savolaine, Mahmoud Daneshmand, peter Hoath (2003) Telecommunications Quality of Service Management, The Instiution of Electrical Engineers, London

2. Arash Shahin (2005) SERVQUAL and Model of Service quality gaps: A frame work for determining and Prioritizing Critical Factors in Delivering Quality of Services, Department of Management, University of Isfahan, Iran. (2005)

3. Asoka Fernando (2005), Regulation and FDI: Sri Lankan Telecommunications Industry, $\mathrm{PhD}$ Candidate, Dept. of Management, Monash University

4. Chungjen Chen and John R. Norsworthy (1998), Measures of Customer Satisfaction and Service Quality in the Telephone Industry, Lally School of Management and Technology, USA

5. Ditech Voice Quality Assurance (VQA) Trial Results, (2005), to Dialog TeleKom, in Sri Lanka, 3rd May 2005, Colombo

6. ITU-T Recommendation E.800 (1994/08) Terms and Definitions related to Quality of service and Network performance including dependability (1995)

7. J.C. Francis and M. Abu EL-Ata, Bench marking Mobile Network QOS, IEEE (2002)

8. J.D. Power and associates 2007, UK mobile Telephone Customer Satisfaction Study, www. jdpower.com

9. Jorge T. Aguiar and Luis M. Correia, A Frariewokk For The Evaluation Of Converged

10. Mobile and Wireless Communication Systems, Technical University of Lisbon

11. Kalum (2003), Measurement Of Service Quality At MTT Networks, Sri Lanka Using The SERVEQUAL Model, MBA/MOT University of Moratuwa, Sri Lanka 
12. Ken Zita and Akash Kapur (2004), Sri Lanka Telecom Brief, USTDA South Asia Communications Infrastructure Conference, New Delhi, India - April 21-23, 2004

13. Parasuraman, A., Zeithaml, V.A. and Berry, L.L. (1993), "Research note: more on improving service quality measurement", Journal of Retailing, Vol. 69, No. 1

14. S.A Rumey Jeffrey (2004), The Perceived quality Gap in Corporate Telecommunications services in Sri Lanka, MBA/IT University of Moratuwa, Sri Lanka

15. Statistics overview of the Telecommunication Sector - Telecommunications Regulatory Commission of SriLanka, available at http:// www.trc.gov.lk/pdf/ statover1.pdf. Accessed on $25 / 08 / 2007$

16. Ville-Veikko Mattila, Semantic analysis of speech quality in mobile communication, Nokia research center, Visiokatu, Finland

17. Vivian Witkind Davis, Larry Blank, David Landsbergen, Nancy Zearfoss,Raymond W. Lawton, John Hoag (1996 March) Telecommunications Service Quality, The National Regulatory Research Institute, The Ohio State University, Ohio (1996) 